\title{
Relationship between arachidonic acid pathway and human renal cell carcinoma
}

\author{
Masahide Matsuyama \\ Rikio Yoshimura \\ Department of Urology, Osaka \\ City University Graduate School \\ of Medicine, Osaka City University \\ Hospital, Abeno-ku, Osaka, Japan
}

\begin{abstract}
Recent epidemiological studies and animal experiments have demonstrated that nonsteroidal antiinflammatory drugs (NSAIDs) reduce the incidence of colorectal carcinoma. Cyclooxygenase (COX) is the principal target of NSAIDs. COX is the first oxidase in the process of prostaglandin production from arachidonic acid. COX enzyme may be involved in the initiation and/or the promotion of carcinogenesis due to NSAIDs inhibition of COX. Lipoxygenase (LOX) is also an initial enzyme in the pathway for producing leukotrienes from arachidonic acid. Similar to COX, LOX enzyme may also be involved in the initiation and/or promotion of carcinogenesis. Peroxisome proliferator activator-receptor (PPAR)- $\gamma$ is a ligand-activated transcriptional factor belonging to the steroid receptor superfamily. PPAR- $\gamma$ plays a role in both adipocyte differentiation and carcinogenesis. PPAR- $\gamma$ is one target for cell growth modulation of NSAIDs. In this review, we report the expression of COX-2, LOX and PPAR- $\gamma$ in human renal cell carcinoma tissues as well as the effects of COX-2 and LOX inhibitors and PPAR- $\gamma$ ligand.
\end{abstract}

Keywords: cyclooxygenase, lipoxygenase, peroxisome proliferator activator-receptor- $\gamma$, renal cell carcinoma

\section{Introduction}

Recently, with increased routine medical check-ups and progress in diagnostic imaging techniques, the discoveries of renal cell carcinoma (RCC) have increased. The cause of RCC is unknown. RCC generally does not respond well to radiotherapy and chemotherapy compared to many other types of cancers, and anticancer drugs as interferon- $\alpha$ and interleukin-2 is used with relative success. So surgery is currently the only therapeutic option. Hence, new molecular targets are needed for the prevention and treatment of RCC.

Nonsteroidal antiinflammatory drugs (NSAIDs) have anticancer effects for the RCC patient, thus, attracting a great deal of attention. The typical target of NSAIDs is cyclooxygenase (COX). In recent reports, a number of patients have had significantly low risks of colorectal cancer while they continued using NSAIDs typified by aspirin. Consequently, the suppression of carcinogenesis by administering NSAIDs has come into focus. It was also reported that the size and number of adenoma were markedly reduced when sulindac, a type of NSAIDs was given to patients with familial adenomatous polyposis, a high risk group for colorectal cancer (Sano et al 1995).

It is known that NSAIDs inhibit the activity of COX and production of prostaglandin. NSAIDs also stimulate peroxisome proliferator activator-receptor (PPAR)- $\gamma$ and inhibit the production of chemical mediators such as tumor necrosis factor- $\alpha$, interleukin- $1 \beta$ and interleukin- 6 through the expression of PPAR- $\gamma$ in leukocytes. PPAR- $\gamma$ is thus a promising target for cell growth modulation by NSAIDs.

In this review, we discuss the possibility that the target of arachidonic acid pathway metabolite may be a new anticancer strategy for human RCC. 


\section{Arachidonic acid pathway}

The metabolism of arachidonic acid by either COX pathway or lipoxygenase (LOX) pathway generates eicosanoids, which have been implicated in the pathogenesis of a variety of human diseases, including cancer, and are considered important in tumor promotion, progression, and metastasis (Yoshimura et al 2003a).

COX is the first enzyme in the pathway for producing prostaglandin $(\mathrm{PG})$ and thromboxane (Tx) from arachidonic acid, and can occur as three isoforms, COX-1, COX-2, and COX-3. The enzymes of both COX-1 and COX-2 are transformed from the cell membrane phospholipid to arachidonic acid by the phospholipase $\mathrm{A}_{2}$, and then transform arachidonic acid to $\mathrm{PGH}_{2}$ through $\mathrm{PGG}_{2}$. COX-1 occurs in tissues and cells and works to protect the cell. COX-2 express momentarily and strongly in response to growth factors and some endotoxins. It is involved with inflammation, cell proliferation and differentiation (Xie et al 1991). Recently, COX-2 has also been shown to play an important role in carcinogenesis (Sano et al 1995). Although the existence of COX-3 has recently been reported, it continues to be argued.

LOX is the first enzyme in the pathway for producing leukotriene (LT) from arachidonic acid. Isoenzymes of LOX include 5-LOX, 12-LOX, and two 15-LOX isoforms (15-LOX-1, 15-LOX-2). These catalyze the biosynthesis of biologically active compounds such as LTs and hydroxyeicosatetraenoic acids (HETEs) (Sigal 1991; Funk 1996). 5-LOX catalyzes the first step in oxygenation of arachidonic acid to produce 5-hydroperoxyeicosatetraenoic acid (5-HPETE), and the subsequent metabolism of 5-HPETE to 5-HETE and LTs. LTs belong to an important group of proinflammatory mediators that are synthesized from arachidonic acid via the 5-LOX pathway. The activity of 5-LOX leads to the formation of unstable $\mathrm{LTA}_{4}$, which can be converted into either $\mathrm{LTB}_{4}$, or cysteinyl LTs $\left(\mathrm{LTC}_{4}, \mathrm{LTD}_{4}\right.$ and $\left.\mathrm{LTE}_{4}\right)$ (Matsuyama et al 2007).

The 12-LOX, includes platelet 12-LOX, and leukocyte 12-LOX that oxygenate arachidonic acid at position C-12 to produce 12-hydroperoxyeicosatetra- enoic acid and then 12-HETE (Yoshimura et al 2003a). Whereas 5-LOX, 12-LOX, and 15-LOX-1, have procarcinogenic roles, 15-LOX-2 appears to have an anticarcinogenic roles.

\section{PPAR}

PPARs are members of the nuclear receptor super-family of ligand-activated transcriptional factor such as steroids, thyroid hormone, vitamin $\mathrm{D}_{3}$ and retinoic acid (Issemann and Green 1990). PPAR binds to peroxisome proliferator response element (PPRE) as a heterodimer with the retinoic receptor (RXR) in the regulation of PPAR target genes. PPARs may be important immunomodulatory factors as well as fatty acid regulators. PPARs modulate these activities in different immune cell types such as monocyte/macrophages, lymphocytes, and endothelial cells.

Three PPAR subtypes $(\alpha, \beta$, and- $\gamma)$ have been identified. PPAR- $\alpha$ is highly expressed in the liver, heart, kidney, muscle, brown adipose tissue, and gut tissues which exhibit high carbolic rates towards fatty acid (Braissant et al 1996). PPAR- $\beta$ is expressed ubiquitously, and its function is relatively unknown (Mukherjee et al 1997). Recent studies suggest that PPAR- $\beta$ may be a target for NSAID-induced tumor suppression in colorectal tumors. PPAR- $\gamma$ is expressed at high-level in adipose tissue and is a critical regular of adipocyte differentiation. In addition, PPAR- $\alpha$ and $-\gamma$ may be important immunomodulatory factors. PPAR- $\alpha$-knockout mice exhibit exacerbated inflammatory responses, and $\mathrm{LTB}_{4}$, a chemotactic mediator, seems to regulate the clearance of itself as an agonist of PPAR- $\alpha$. PPAR- $\gamma$ is also expressed in the immune system tissues and cells (spleen, bone-marrow, monocytes, helper T-cell clones) and skeletal tissues (bone, synovioum, chondrocytes) (Braissant et al 1996).

Recent data have shown that PPAR- $\gamma$ ligands lead to inhibition of phorbol ester-induced nitric oxide and macrophage-derived cytokines. PPAR- $\gamma$ ligands also induce apoptosis in macrophage, fibroblasts, and endothelial cells (Kawahito et al 2000). PPAR- $\gamma$ plays a role in both adipocyte differentiation and carcinogenesis. PPAR- $\gamma$ ligands lead to inhibition of the expression of nitric oxide, cytokines, chemokines and adhesion molecules, in part by antagonizing the activities of transcriptional factors. Furthermore, PPAR- $\gamma$ ligands including antidiabetic thiazolidinedione (such as troglitazone) and 15-deoxy- $\Delta^{12,14}$-prostaglandin $\mathrm{J}_{2}$ (15-d-PGJ ${ }_{2}$ ) have potent tumor modulatory effects on several cancers (Tsubouchi et al 2000; Inoue et al 2001).

\section{COX and RCC}

COX-2 expression in RCC tissues was stronger than in the normal kidney (NK) tissues by immunohistochemical staining (Figure 1) (108 RCC and 20 NK tissues) or reverse transcriptase polymerase chain reaction (RT-PCR). We classified 3 categories (epithelium, blood vessel, a small quantity of stromal tissue) in RCC tissues, and examined them for intensity of COX-2 expression. COX-2 expression was more intensive and extensive in all categories of RCC tissues than NK tissues. Significant differences occurred between grades of RCC tissues in only epithelium in COX-2 expression. 

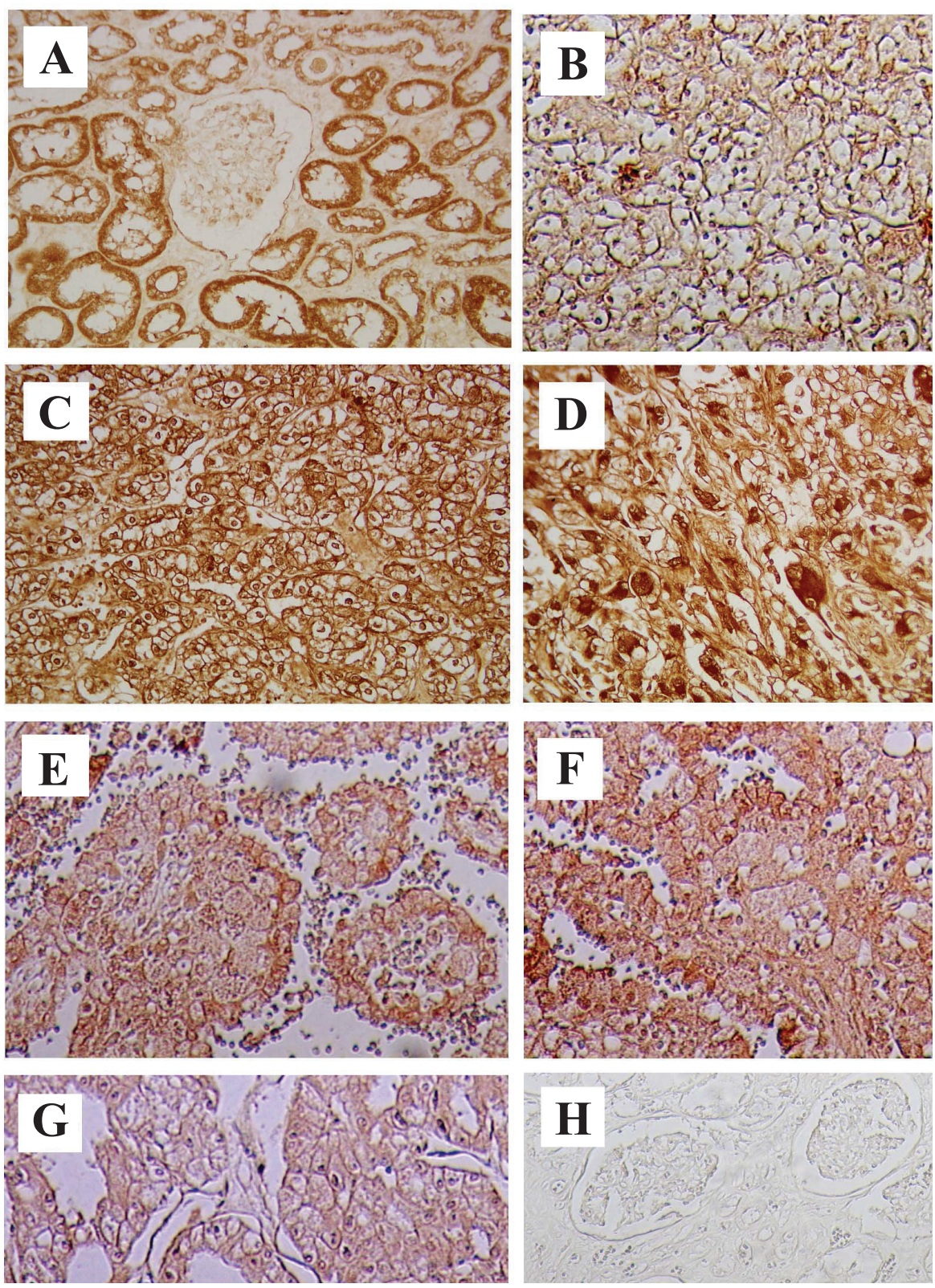

Figure I COX-2 immunostaining in RCC and normal kidney (NK) tissues. COX-2 was strongly expressed in all slides from cancer specimens, clear cell RCC -GI, -G2 and G3 (B, C and D) and other types of RCC tissues (E; papillary RCC G3, F; collecting duct carcinoma chromophobe RCC G2, G; chromophobe RCC G2). No expression of COX-2 was detected in NK tissue $(\mathbf{A})$. Immunostaining with PBS was negative $(\mathbf{H})$.

COX-2 expression was stronger in high differentiation RCC (Yoshimura et al 2004a).

Hashimoto and colleagues (2004) reported COX-2 expression was strong in RCC by immunohistochemical staining, and there was a correlation between the expression of COX-2, grade and stage. Miyata and colleagues (2003) reported there was only correlation between COX-2 expression and more than $7 \mathrm{~cm}$ length tumor by immunohistochemical straining. Mungan and colleagues (2006) reported COX-2 expression was significantly higher in RCC and renal intratubular neoplasia than the normal and pyelonephritic cases by immunohistochemisty. Sozen and colleagues (2007) reported RCC patients with higher immunohistochemical COX-2 staining score values have significantly shorter progression-free survival rates.

The establishment of cancer tissue requires that it should permeate through the mucosa and the submucosa after it destroys the basement membrane. Consequently, the destructive action of tumor cells on the basement membrane is an integral part in the development of a tumor in its first 
stage, and the activation of matrix meta protease is essential for the destruction of the basement membrane. Miyata and colleagues (2003) reported the correlation between the development of the RCC and the activation of matrix meta protease2 based on its involved with the expression of COX-2 in the tumor. Smyth and colleagues (2003) reported RCC depresses the immunocompetence, and vascularization, while producing $\mathrm{PGE}_{2}$ in the development of tumor growth.

Cyclooxygenase-2 (COX-2) and vascular endothelial growth factor (VEGF) are frequently up-regulated in malignant tumors and play a role in proliferation, apoptosis, angiogenesis and tumor invasion. Hemmerlein and colleagues (2004) reported COX-2 and VEGF are expressed in RCC and associated cell populations such as endothelia and monocytes/macrophages by RT-PCR and immunohistochemistry.

A recently accepted explanation is that only celecoxib, among the COX-2 inhibitors induces apoptosis of cancer cells. Rini and colleagues (2006) reported maximal COX-2 tumor immunostaining might identify RCC patents more likely to achieve clinical benefit with $\mathrm{COX}-2$ inhibition by celecoxib in combination with interferon- $\alpha$.

In our experiment, we could not demonstrate significant apoptosis induction by administering eight kinds of COX-2 inhibitors into the human RCC cell line (Caki-1) (Table 1). Additionally, we could not demonstrate the significance of both selective COX-2 inhibitor (etodolac, meloxicam, nimesulide and NS398) and relatively poor selective COX-2 inhibitor (ibuprofen, indomethacin, piroxicam and s-naparoxen) (Yoshimura et al 2004b).

In conclusion, COX-2 expression is strong in RCC, but the anticancer effect of COX-2 inhibitor is very weak in RCC patients in a single administration at a clinical dose. COX-2 inhibitor is suitable for chemopreventive therapy.

\section{LOX and RCC}

We have shown that 5- and 12-LOX expressions in RCC tissues were stronger than those in NK tissues by immunohistochemical staining (50 RCC and $10 \mathrm{NK}$ tissues) and RT-PCR (Figure 2). We classified 3 categories (epithelium, blood vessel, a small quantity of stromal tissue) in RCC tissues and NK tissues, and examined the intensity of 5- and 12-LOX expressions. 5- and 12-LOX expressions were more intensive and extensive in all categories of RCC tissues as compared with NK tissues (Table 2). There were significant differences only epithelium in RCC tissues, and 5- and 12-LOX expressions were stronger in high differentiation RCC (Matsuyama et al 2005).

Table I Effects of COX and LOX inhibitors, and PPAR- $\gamma$ ligand in viabity of human RCC cell line (Caki-I)

\begin{tabular}{|c|c|c|c|c|c|}
\hline & $5 \mu \mathrm{M}$ & $10 \mu \mathrm{M}$ & $20 \mu \mathrm{M}$ & $40 \mu \mathrm{M}$ & $80 \mu \mathrm{M}$ \\
\hline \multicolumn{6}{|l|}{ COX-2 inhibitor } \\
\hline \multicolumn{6}{|l|}{ Selective COX-2 inhibitor } \\
\hline Etodolac & not shown & $116.6 \%$ & $114.4 \%$ & $95.7 \%$ & $96.3 \%$ \\
\hline Meloxicam & not shown & $115.2 \%$ & $106.0 \%$ & $99.5 \%$ & $68.2 \%$ \\
\hline Nimesulide & not shown & $96.0 \%$ & $104.2 \%$ & $103.1 \%$ & $93.5 \%$ \\
\hline NS398 & not shown & $110.5 \%$ & $86.1 \%$ & $79.8 \%$ & $73.2 \%$ \\
\hline \multicolumn{6}{|l|}{ Poor selective COX-2 } \\
\hline \multicolumn{6}{|l|}{ inhibitor } \\
\hline Ibuprofen & not shown & $108.4 \%$ & $108.7 \%$ & $104.9 \%$ & $110.2 \%$ \\
\hline Indometacin & not shown & $114.1 \%$ & $112.9 \%$ & $114.0 \%$ & $102.9 \%$ \\
\hline Piroxicam & not shown & $87.4 \%$ & $96.7 \%$ & $85.8 \%$ & $83.3 \%$ \\
\hline S-naproxen & not shown & $95.2 \%$ & $102.8 \%$ & $103.1 \%$ & $93.5 \%$ \\
\hline \multicolumn{6}{|l|}{ LOX inhibitor } \\
\hline 5-LOX inhibitor (Caffeic acid) & not shown & $92.4 \%$ & $68.3 \%$ & $21.7 \%$ & $16.6 \%$ \\
\hline I2-LOX inhibitor (Baicalein) & not shown & $103.5 \%$ & $98.7 \%$ & $75.2 \%$ & $40.6 \%$ \\
\hline $\begin{array}{l}\text { Non selective LOX inhibitor } \\
\text { (NDGA) }\end{array}$ & not shown & $72.5 \%$ & $28.7 \%$ & $8.6 \%$ & $9.8 \%$ \\
\hline \multicolumn{6}{|l|}{ PPAR- $\gamma$ ligand } \\
\hline Troglitazone & $22.1 \%$ & $16.6 \%$ & $13.4 \%$ & $10.7 \%$ & not shown \\
\hline I5-d-PGJ2 & $69.8 \%$ & $54.2 \%$ & $20.3 \%$ & $16.8 \%$ & not shown \\
\hline
\end{tabular}

Notes: The dose-response analysis of viability in human RCC cell line (Caki-I) treated with COX-2 and LOX inhibitors, and PPAR- $\gamma$ ligand (5-80 $\mu$ M, 48 hr) was measured by the MTT assay and expressed as \% of control culture conditions. 


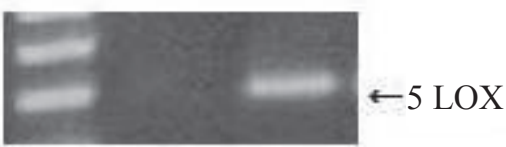

Lane $\quad 1 \quad 2 \quad 3$

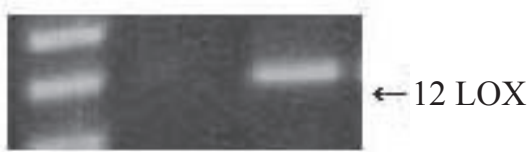

Lane $1 \quad 2 \quad 3$

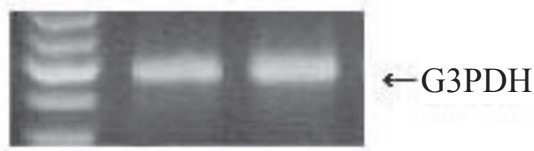

Lane $\quad 1 \quad 2 \quad 3$

Figure 2 RT-PCR analysis of 5- and I 2-LOX in RCC tissues and normal kidney (NK) tissues. Using specific primers for 5-LOX, I2-LOX and G3PDH, the amplification predicted fragments of 337 bp for 5-LOX, 345 bp for 12-LOX and 598 bp for G3PDH in length. A; 5-LOX, B; I 2-LOX, C; G3PDH. Lane I; markers, Lane 2; NK tissues, Lane 3; RCC tissues. RCC tissues expressed significant 5- and 12-LOX mRNA bands while NK tissues expressed no 5- and I2-LOX mRNA bands.

At 10-80 $\mu \mathrm{M}$, some, but not all LOX inhibitors reduced the viability of RCC cell line (Caki-1) by MTT assay (Table 1). 5-LOX inhibitor appeared more potent than the 12-LOX inhibitor (Matsuyama et al 2004). RCC cells treated with some LOX inhibitor $(50 \mu \mathrm{M})$ also showed chromatin condensation, cellular shrinkage, apoptotic bodies and cytoplasmic condensation by hoechest staining (Figure 3). RCC cells treated with 5-LOX inhibitor $(100 \mu \mathrm{M})$ entered early apoptosis, but not late apoptosis, necrosis or DNA fragmentation by flow cytometry. However, PPAR- $\gamma$ ligands did not cause normal proximal tubular endothelial cells (PRTEC) to undergo apoptosis.

Faronato and colleagues (2007) reported increased 5-LOX protein and mRNA correlated with large tumor size $(>4 \mathrm{~cm})$ and age of patients. In contrast, there was no association between 5-LOX and gender, grade or vein invasion by quantitative PCR. VEGF expression was strongly inducible by 5 -LOX metabolites in RCC cell lines. They suggest that 5-LOX up-regulation is an important step in RCC progression (Faronato et al 2007).

In conclusion, 5-LOX expression is strong in RCC. The anticancer effect of 5-LOX inhibitor is significantly stronger than those of COX-2 inhibitor. The anticancer effect of 5-LOX inhibitor is weak in RCC patients in a single administration at a clinical dose. 5-LOX inhibitor is suitable for chemopreventative therapy, like COX-2 inhibitor.

\section{PPAR- $\gamma$ and RCC}

By immunohistochemical staining (126 RCC and $20 \mathrm{NK}$ tissues) and RT-PCR, PPAR- $\gamma$ expression was increased in RCC tissues as compared with NK tissues (Inoue et al 2001). All categories (epithelium, blood vessel, a small quantity of stromal tissue) of RCC tissues were more extensive than NK tissues in PPAR- $\alpha,-\beta$, and $-\gamma$ expression. There were no significant differences between grades and stages of RCC tissues in all categories in PPAR- $\alpha$, and - $\beta$ expression. However, PPAR- $\gamma$ expression was higher in G1 cancer than in G3 cancer, and there were no significant differences among stages.

The PPAR- $\gamma$ ligands troglitazone and $15-\mathrm{d}-\mathrm{PGJ}_{2}$ induced the reduction of RCC cell line (Caki-1) viability in the range of $10-40 \mu \mathrm{M}$ by using MTT assay (Table 1). RCC cells treated with PPAR- $\gamma$ ligands $\left(25 \mu \mathrm{M}\right.$ troglitazone and $\left.15-\mathrm{d}-\mathrm{PGJ}_{2}\right)$ entered early apoptosis, but not late apoptosis, necrosis or DNA fragmentation by flow cytometry. However, PPAR- $\gamma$ ligands did not cause normal proximal tubular endothelial cells (PRTEC) to undergo apoptosis (Figures 4, 5). PPAR- $\gamma$ ligands also induced apoptosis in RCC cells at $20 \mu \mathrm{M}$ by hoechest staining (Yoshimura et al 2003b).

Yang and colleagues (2005) reported PPAR- $\gamma$ was expressed at much higher levels in RCC than in NK. PPAR- $\gamma$ ligands (troglitazone) inhibited RCC cell growth in a dose-dependent manner. Generally, Bcl-2 is a key factor suppressing the apoptosis accompanying of caspase. Consistent with our findings, they also reported $50 \mu \mathrm{M}$ troglitazone induced massive apoptosis in RCC cells with decreased Bcl-2 expression (Yang et al 2005). Yuan and colleagues (2005) reported that PPAR- $\gamma$ were expressed in RCC cell lines by RT-PCR and immunocytochemical staining. PPAR- $\gamma$ ligands inhibited the cell growth in all cells in a dose-dependent manner through apoptosis. Secretion of both VEGF and basic fibroblast growth factor was inhibited by PPAR- $\gamma$ ligands in a dose-dependent and time-dependent manner (Yuan et al 2005). They also reported that PPAR- $\gamma$ mRNA expression in RCC cells did not affect cell growth inhibition by PPAR- $\gamma$ ligands (Yuan et al 2006).

In conclusion, PPAR- $\gamma$ is strongly expressed in RCC, and the anticancer effect of PPAR- $\gamma$ ligand is significantly greater than that of 5-LOX inhibitor. The anticancer effect of PPAR- $\gamma$ ligand is relatively weak. Targeting PPAR- $\gamma$ in 
Table 2 Statistical analysis of 5-LOX and I2-LOX immunostaining

\begin{tabular}{clll}
\hline & Epithelium & Blood vessel & Stromal tissue \\
\hline 5 -LOX & & & $2.7 \pm 0.7^{*}$ \\
RCC & $2.8 \pm 0.8^{*}$ & $2.6 \pm 0.6^{*}$ & $2.9 \pm 0.7^{*}$ \\
GI & $3.2 \pm 0.7^{*}$ & $2.8 \pm 0.6^{*}$ & $2.6 \pm 0.7^{*}$ \\
G2 & $2.6 \pm 0.6^{*}$ & $2.4 \pm 0.5^{*}$ & $2.3 \pm 0.4^{*}$ \\
G3 & $1.9 \pm 0.5^{*}$ & $2.3 \pm 0.4^{*}$ & $0.6 \pm 0.5$ \\
Normal kidney (NK) & $0.6 \pm 0.4$ & $0.5 \pm 0.4$ & $2.1 \pm 0.6^{*}$ \\
I2-LOX & & & $2.2 \pm 0.7^{*}$ \\
RCC & $2.4 \pm 0.7^{*}$ & $2.2 \pm 0.5^{*}$ & $2.0 \pm 0.5^{*}$ \\
GI & $2.8 \pm 0.5^{*}$ & $2.3 \pm 0.6^{*}$ & $1.9 \pm 0.3^{*}$ \\
G2 & $2.2 \pm 0.6^{*}$ & $2.1 \pm 0.6^{*}$ & $0.6 \pm 0.4$ \\
G3 & $1.7 \pm 0.5^{*}$ & $2.1 \pm 0.3^{*}$ & $0.6 \pm 0.4$ \\
Normal kidney (NK) & $0.5 \pm 0.4$ & & \\
\hline
\end{tabular}

Notes: Graded 0-4 on the coded sections by two observers in a blinded manner. 0, no staining; 4, maximum intensity. Statistical analysis was performed using the ANOVA (p-value). 5- and I2-LOX immunostaining was significantly more extensive and intense in tumor cells than in tissue of normal kidney. (*P $<0.00 \mathrm{I})$.
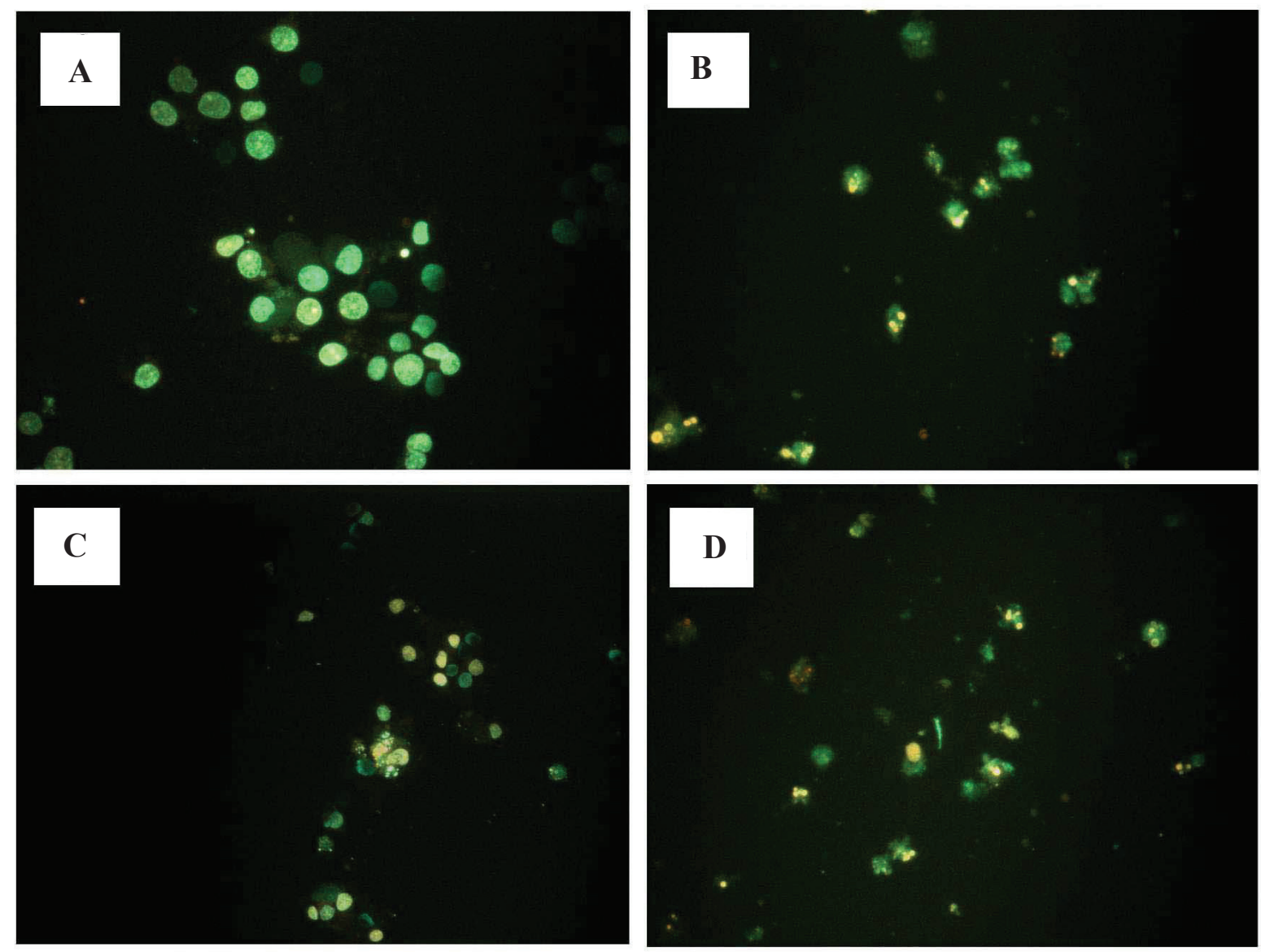

Figure 3 Effects of LOX inhibitor in induction of apoptosis on RCC cells. Human RCC cell line (Caki-I) treated with 5-LOX inhibitor caffeic acid (B), and nonspecific LOX inhibitor NDGA (D) showed chromatin condensation, cellular shrinkage, small membrane-bound bodies (apoptotic bodies), and cytoplasmic condensation. Cells with 12-LOX inhibitor baicalein only slightly showed the same apoptotic changes (C). In contrast, untreated cells (A) maintained normal chromatin patterns and cell size. 
Caki-1
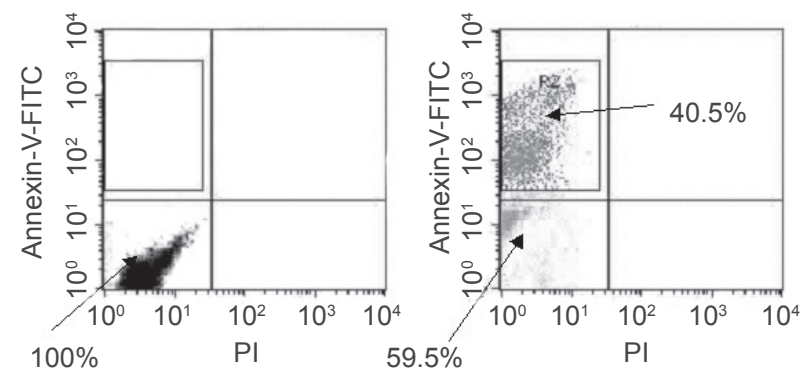

PRTEC Control

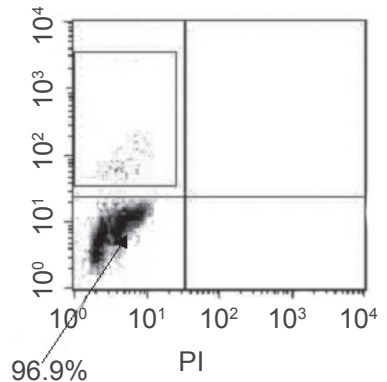

Control
$25 \mu \mathrm{M}$ PPAR ligand $\left(15-d-P G J_{2}\right)$

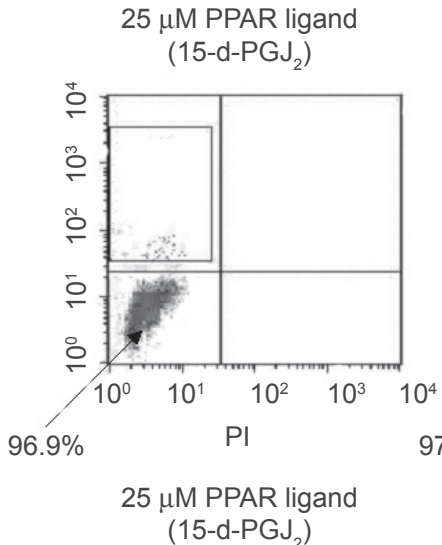

$\left(15-d-P G J_{2}\right)$

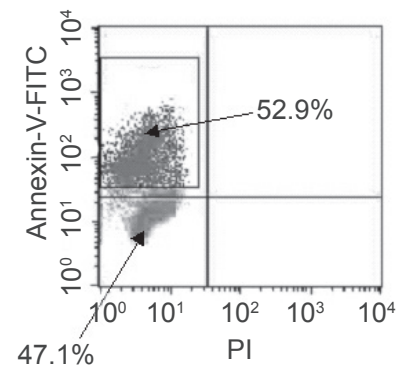

$25 \mu \mathrm{M}$ PPAR ligand (Troglitazone)

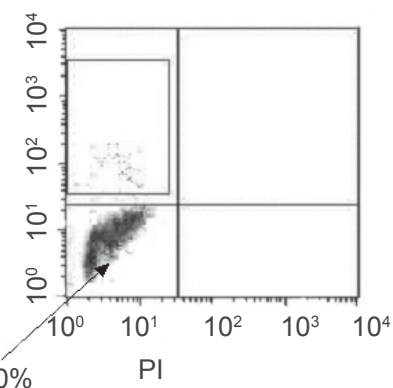

$25 \mu \mathrm{M}$ PPAR ligand (Troglitazone)

Figure 4 Effects of PPAR- $\gamma$ ligand on apoptosis by flow cytometry in RCC cells. Human RCC cell line (Caki-I) with treatment of PPAR- $\gamma$ ligand (25 $\mu$ M troglitazone and I5-d-PG $\left.\right|_{2}$ ) could induce early apoptosis not late apoptosis or necrosis. PPAR- $\gamma$ ligand $(25 \mu \mathrm{M})$ did not cause normal proximal tubular endothelial cells (PRTEC) to undergo apoptosis. The top left quadrants represent early apoptosis (Annexin V-FITC-positive cells and PI-negative cells). The top right quadrants represent late apoptosis or necrosis (Annexin V-FITC-positive cells and PI-positive cells). Diagrams of FITC-Annexin V/PI flow cytometry are presented.

\section{Caki-1}

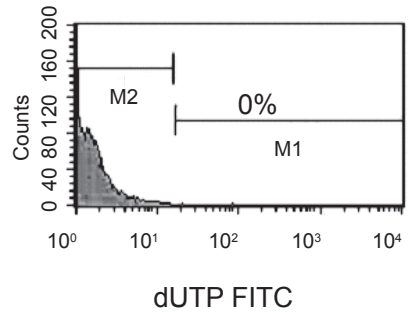

Control

PRTEC

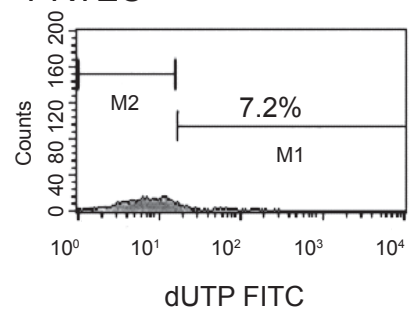

Control

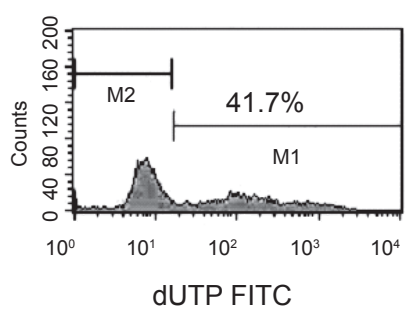

$25 \mu \mathrm{M}$ PPAR ligand

$\left(15-d-P G J_{2}\right)$

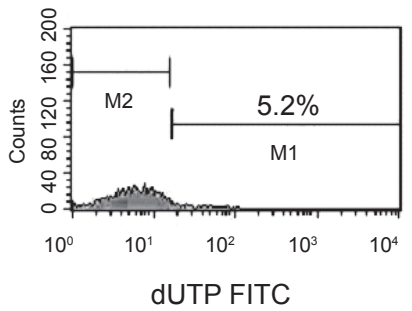

$25 \mu \mathrm{M}$ PPAR ligand $\left(15-d-P G J_{2}\right)$

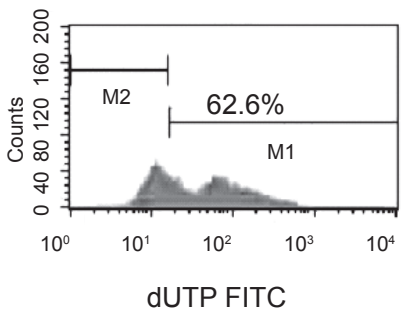

$25 \mu \mathrm{M}$ PPAR ligand (Troglitazone)

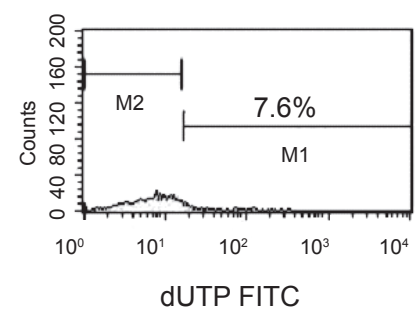

$25 \mu \mathrm{M}$ PPAR ligand (Troglitazone)

Figure 5 PPAR- $\gamma$ ligand induced DNA fragmentation in RCC cells. PPAR- $\gamma$ ligand (25 $\mu$ M troglitazone and I5-d-PG ${ }_{2}$ ) could induce DNA fragmentation in human RCC cell line (Caki-I). PPAR- $\gamma$ ligand $(25 \mu \mathrm{M})$ did not cause normal proximal tubular endothelial cells (PRTEC) to undergo apoptosis. Typical flow cytometry analysis histograms are presented. 
$\mathrm{RCC}$ is likely to be useful more as chemopreventive rather than a chemotherapeutic.

\section{Conclusions}

There is no argument that COX-2, LOX (especially, 5-LOX) PPAR- $\gamma$ are involved in the initiation and promotion of RCC tissues. It may be possible to use COX-2 and 5-LOX inhibitors, and PPAR- $\gamma$ ligand as anticancer drugs for chemopreventive therapy in a single administration of a clinical dose. However, it may be difficult to use COX-2 and 5-LOX inhibitors, even with PPAR- $\gamma$ ligand in single administration of a clinical dose as a potential chemotherapeutic therapy. The clinical application of PPAR- $\gamma$ ligand and 5-LOX inhibitor require further research and consideration, as the target of PPAR- $\gamma$ ligand and 5-LOX inhibitor remains a novel strategy in treating human RCC.

We conclude the administration of COX-2 and 5-LOX inhibitor, and PPAR- $\gamma$ ligand are useful along with conventional treatment of human RCC. The combination therapy of COX-2 and 5-LOX inhibitor, and PPAR- $\gamma$ ligand may be a beneficial new treatment of human RCC.

\section{Disclosure}

The authors report no conflicts of interest in this work.

\section{References}

Braissant O, Foufelle F, Scotto C, et al. 1996. Differential expression of peroxisome proliferator-activated receptors (PPARs). Tissue distribution of PPAR-alpha, -beta, and -gamma in the adult rat. Endocrinology, 137:354-66.

Faronato M, Muzzonigro G, Milanese G, et al. 2007. Increased expression of 5-lipoxygenase is common in clear cell renal cell carcinoma. Histol Histopathol, 22:1109-18.

Funk CD. 1996. The molecular biology of mammalian lipoxygenases and the quest for eicosanoid functions using lipoxygenase-deficient mice. Biochim Biophys Acta, 11:65-84.

Hashimoto Y, Kondo Y, Kimura G, et al. 2004. Cyclooxygenase-2 expression and relationship to tumour progression in human renal cell carcinoma. Histopathology, 44:353-9.

Hemmerlein B, Galuschka L, Putzer N, et al. 2004. Comparative analysis of COX-2, vascular endothelial growth factor and microvessel density in human renal cell carcinomas. Histopathology, 45:603-11.

Inoue K, Kawahito Y, Tsubouchi Y, et al. 2001. Expression of peroxisome proliferator-activated receptor gamma in renal cell carcinoma and growth inhibition by its agonists. Biochem Biophys Res Commun, 287:727-32.

Issemann I, Green S. 1990. Activation of a member of the steroid hormone receptor superfamily by peroxisome proliferator. Nature, 347:645-50

Kawahito Y, Kondo M, Tsubouchi Y, et al. 2000. 15-deoxy-delta(12,14)-PGJ(2) induces synoviocyte apoptosis and suppresses adjuvant-induced arthritis in rats. J Clin Invest, 106:189-97.
Matsuyama M, Hayama T, Funao K, et al. 2007. Overexpression of cysteinylLT1 receptor in prostate cancer and CysLT1R antagonist inhibits prostate cancer cell growth through apoptosis. Oncol Rep, 18:99-104.

Matsuyama M, Yoshimuira R, Tsuchida K, et al. 2004. Lipoxygenase inhibitors prevent urological cancer cell growth. Int $J \mathrm{Mol} \mathrm{Med,}$ 13:665-8.

Matsuyama M, Yoshimura R, Mitsuhashi M, et al. 2005. 5-lipoxygenase inhibitors attenuate growth of human renal cell carcinoma and induce apoptosis through arachidonic acid pathway. Oncol Rep, 14:73-9.

Miyata Y, Koga S, Kanda S, et al. 2003. Expression of cyclooxygenase-2 in renal cell carcinoma: correlation with tumor cell proliferation, apoptosis, angiogenesis, expression of matrix metalloproteinase-2, and survival. Clin Cancer Res, 9:1741-9.

Mukherjee R, Jow L, Croston GE, et al. 1997. Identification, characterization, and tissue distribution of human peroxisome proliferator-activated receptor (PPAR) isoforms PPARgamma2 versus PPARgamma1 and activation with retinoid $\mathrm{X}$ receptor agonists and antagonists. $J$ Biol Chem, 272:8071-6.

Mungan MU, Gurel D, Canda AE, et al. 2006. Expression of COX-2 in normal and pyelonephritic kidney, renal intraepithelial neoplasia, and renal cell carcinoma. Eur Urol, 50:23-5.

Rini BI, Weinberg V, Dunlap S, et al. 2006. Maximal COX-2 immunostaining and clinical response to celecoxib and interferon alpha therapy in metastatic renal cell carcinoma. Cancer, 106:566-75.

Sano H, Kawahito Y, Wilder RL, et al. 1995. Expression of cyclooxygenase-1 and -2 in human colorectal cancer. Cancer Res, 55:3785-9.

Sigal E. 1991. The molecular biology of mammalian arachidonic acid metabolism. Am J Physiol, 260:13-28.

Smyth GP, Stapleton PP, Barden CB, et al. 2003. Renal cell carcinoma induces prostaglandin $\mathrm{E} 2$ and T-helper type 2 cytokine production in peripheral blood mononuclear cells. Ann Surg Oncol, 10:455-62.

Sozen S, Gurocak S, Erdem O, et al. 2007. Cyclooxygenase-2 expression: Does it have a probable role in tumorigenesis mechanisms of renal cell carcinoma? Int Urol Nephrol, 26.

Tsubouchi Y, Sano H, Kawahito Y, et al. 2000. Inhibition of human lung cancer cell growth by the peroxisome proliferator-activated receptor- $\gamma$ agonists through induction of apoptosis. Biochem Biophys Res Commun, 270:400-5.

Xie W, Chipman JG, Robertson DL, et al. 1991. Expression of a mitogen-responsive gene encoding prostaglandin synthase is regulated by mRNA splicing. Proc Natl Acad Sci U S A, 88:2692-6.

Yang FG, Zhang ZW, Zin DQ, et al. 2005. Peroxisome proliferator-activated receptor gamma ligands induce cell cycle arrest and apoptosis in human renal carcinoma cell lines. Acta Pharmacol Sin, 26:753-61.

Yoshimura R, Matsuyama M, Hase T, et al. 2003b. The effect of peroxisome proliferator-activated receptor-gamma ligand on urological cancer cells. Int $J$ Mol Med, 12:861-5.

Yoshimura R, Matsuyama M, Kawahito Y, et al. 2004a. Study of cyclooxygenase-2 in renal cell carcinoma. Int J Mol Med, 13:229-33.

Yoshimura R, Matsuyama M, Kawahito Y, et al.2004b. The effect of cyclooxygenase-2 inhibitors on urological cancer cells. Int J Mol Med, 13:789-93.

Yoshimura R, Matsuyama M, Tsuchida K, et al.2003a. Expression of lipoxygenase in human bladder carcinoma and growth inhibition by its inhibitors. $J$ Urol, 170:1994-9.

Yuan J, Takahashi A, Masumori N, et al. 2005. Ligands for peroxisome proliferator-activated receptor gamma have potent antitumor effect against human renal cell carcinoma. Urology, 65:594-9.

Yuan J, Takahashi A, Masumori N, et al. 2006. Peroxisome proliferatoractivated receptor gamma is frequently underexpressed in renal cell carcinoma. Int J Urol, 13:265-70. 